\title{
Optimization of surgical referrals to minimize cost
}

Keywords: surgical referrals, podiatry surgeries, orthopedic

\section{Introduction}

The main region for this study includes all of New Mexico and West Texas, which is mainly served by the Albuquerque surgical department located in Albuquerque New Mexico. The focus of this study is on the surgical referrals to the Albuquerque surgical suite from three main areas including West Texas, North Albuquerque and South Albuquerque.

Albuquerque hospital serves an area, which includes all of New Mexico, Arizona and West Texas area. There are two level one facilities in this region serving the patients who need access to surgery. One facility is located in Tucson, which serves patients in Arizona and one in Albuquerque, which serves patients in New Mexico and West Texas. Patients who live in Southern or Northern New Mexico and West Texas who require non-emergency surgery are referred to the Albuquerque Medical Center surgical department. All emergency surgeries are referred to the nearest clinic or hospital with surgical capability for the procedure provided fee-care availability.

The Albuquerque Medical Center surgical Department not only serves the surgical needs of the local and nearby community, but also has to schedule all non-emergency referrals from the rest of New Mexico and West Texas. The Surgical Department follows a block schedule for various departments accessing the nine OR rooms. Two departments, which have significant non-emergency surgical referrals from outside Albuquerque, include Orthopedic and Podiatry surgeries. Orthopedic department has been allocated four surgical rooms on Mondays, Tuesdays, Thursdays, and Fridays for a total of 82 hours of access per week to OR. The Podiatry has been allocated three surgical rooms on Mondays, Wednesdays, and Fridays for a total of 19 hours of access per week to OR.

The referral patients will also have pre and post-surgery visits to the Albuquerque Medical center and in most cases, travel is reimbursed. Considering the volume of referral patients for these departments and the cost associated with the referrals, it may be feasible to build additional clinics or Medical centers with surgical capability in areas

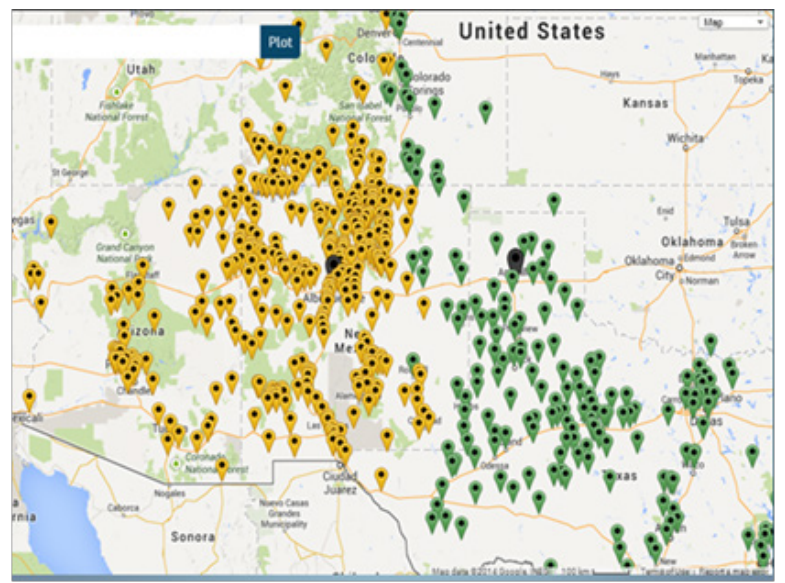

Figure I A new clustering scheme was obtained based on an additional two random initial seeds.
Volume 2 Issue 3 - 2018

Kambiz Farahmand, Satpal Singh Wadhwa

North Dakota State University, USA

Correspondence: Kambiz Farahmand, Professor, North Dakota State University, 1410 14th Ave N, Fargo, ND 58102 USA,Tel 70I-23I-5694,Email Frahmand@ndsu.edu

Received: April 18, 2018 | Published: May 07, 2018

such as West Texas or other locations in Albuquerque.

It is the purpose of this project to simulate and determine the actual cost associated with surgical referrals to the Albuquerque surgical department for the said procedures and to analyze the feasibility of increased capability specifically in orthopedic and Podiatry surgery within the referral area. From analyzing the hospital admission data, it was found that there are 8678 patients that will not receive reimbursement at all for all procedures and 1997 patients get full reimbursement for all procedures. This shows that the patients are not reimbursed might not fit in the reimbursement policy and those getting full reimbursement for the different procedures on the same day might be falling in some special criteria of the reimbursement policy. Furthermore, the procedures reimbursed may also carry different weights as per reimbursement policy. This concludes that the variations in the procedures types and the patient with respect to reimbursement could not be ignored for cost modeling. Therefore, the management should provide the details of the reimbursement policy. ${ }^{1,2}$

\section{Methodology}

Once the data is validated for reimbursement policies by the management the $\mathrm{K}$ means clustering is done to get the optimal clusters and to find the location of new health care facility. Based on previous clustering using two specified initial seeds at Amarillo and Albuquerque the following patient demographic map was obtained (Figures 1-3).

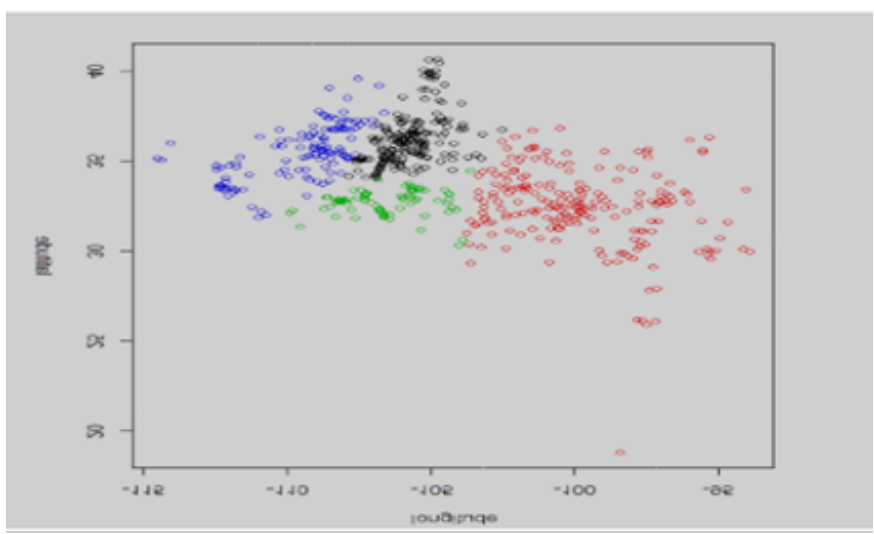

Figure 2 Another cluster was obtain shown below, based on an additional two random initial seeds and adding the constraint of only three clusters. 


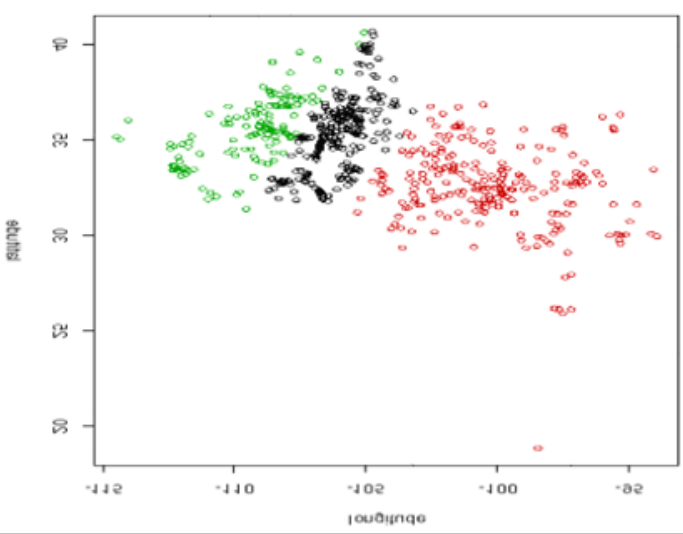

Figure 3 Finally, the optimization model could be used to decide between the various alternative.

Finally, the optimization model could be used to decide between the various alternative. Table below shows the distributions depicting distances from each cluster to Albuquerque for patient's admission, consultation, and procedures performed (Tables 1-6). ${ }^{3,4}$

Table I Distribution of patients for each cluster

\begin{tabular}{|c|c|c|c|}
\hline & & Original & Adjusted \\
\hline \multirow[t]{5}{*}{ Orthopedic } & Cluster I & $-0.5+\operatorname{EXPO}(1.97)$ & $-0.5+\operatorname{EXPO}(I .5)$ \\
\hline & Cluster 2 & No patients admitted & $\begin{array}{l}\text { No patients } \\
\text { admitted }\end{array}$ \\
\hline & Cluster 3 & $\begin{array}{l}-0.5+18^{*} \\
\operatorname{BETA}(0.886,4.27)\end{array}$ & $\begin{array}{l}-0.5+18^{*} \\
\operatorname{BETA}(0.703,4.27)\end{array}$ \\
\hline & Cluster 4 & $\begin{array}{l}-0.5+\text { GAMM(6.33, } \\
\text { I.19) }\end{array}$ & $\begin{array}{l}-0.5+\text { GAMM(5.275 } \\
\text { I.19) }\end{array}$ \\
\hline & Cluster 5 & 4 + WEIB $(4 I .4,0.54)$ & 4 +WEIB $(4 \mid .4,0.54)$ \\
\hline \multirow[t]{5}{*}{ Podiatry } & Cluster I & $\begin{array}{l}-0.5+\text { WEIB }(8.88 \\
\mathrm{I} .12)\end{array}$ & $\begin{array}{l}-0.5+\text { WEIB }(7.4, \\
\mathrm{I} .12)\end{array}$ \\
\hline & Cluster 2 & No patients admitted & $\begin{array}{l}\text { No patients } \\
\text { admitted }\end{array}$ \\
\hline & Cluster 3 & $\begin{array}{l}-0.001+107 * \\
\operatorname{BETA}(0.349,0.717)\end{array}$ & $\begin{array}{l}-0.001+107 * \\
\operatorname{BETA}(0.1,0.717)\end{array}$ \\
\hline & Cluster 4 & $\begin{array}{l}33+\text { GAMM }(445, \\
0.248)\end{array}$ & $\begin{array}{l}33+\text { GAMM }(445 \\
0.248)\end{array}$ \\
\hline & Cluster 5 & Constant 443 & $\begin{array}{l}-0.5+91 * \\
\operatorname{BETA}(8.17,0.1)\end{array}$ \\
\hline
\end{tabular}

Table 2 Results using rate for consultation

\begin{tabular}{llll}
\hline Consultation & Simulation & Actual & $\begin{array}{l}\text { Percentage } \\
\text { error }\end{array}$ \\
\hline $\begin{array}{l}\text { Total Number } \\
\text { Total Number }\end{array}$ & 11428.23 & 15357 & $-25.58 \%$ \\
$\begin{array}{l}\text { Reimbursed } \\
\text { Consultation Total } \\
\text { Cost }\end{array}$ & 4086.07 & 15311.7 & $-73.31 \%$ \\
\hline
\end{tabular}

Table 3 Results using rate for procedure

\begin{tabular}{llll}
\hline Procedure & Simulation & Actual & $\begin{array}{l}\text { Percentage } \\
\text { error }\end{array}$ \\
\hline $\begin{array}{l}\text { Total Number } \\
\begin{array}{l}\text { Total Number } \\
\text { Reimbursed }\end{array}\end{array}$ & 53573.8 & 75485 & $-29.03 \%$ \\
Procedure Total Cost & $\$ 9598.6$ & 31814.1358 & $-38.40 \%$ \\
\hline
\end{tabular}

Table 4 Results using rate for admits

\begin{tabular}{llll} 
Admission & Simulation & Actual & Percentage error \\
\hline Total Number & 728.23 & 1021 & $-28.67 \%$ \\
$\begin{array}{l}\text { Total Number } \\
\text { Reimbursed }\end{array}$ & 353.2 & 1021 & $-65.41 \%$ \\
$\begin{array}{l}\text { Admission Total } \\
\text { Cost }\end{array}$ & $\$ 39,372.35$ & & \\
\hline
\end{tabular}

Table 5 Results using rate for all patients

\begin{tabular}{llll}
\hline Total & Simulation & Actual & $\begin{array}{l}\text { Percentage } \\
\text { error }\end{array}$ \\
\hline $\begin{array}{l}\text { Total number of } \\
\text { observation }\end{array}$ & 65,730 & 91863 & $-28.45 \%$ \\
$\begin{array}{l}\text { Total cost } \\
\begin{array}{l}\text { Total number } \\
\text { reimbursed }\end{array}\end{array}$ & $\$ 1,732,970.55$ & $\$ 2272990.77$ & $-23.76 \%$ \\
\hline
\end{tabular}

Table 6 Idle percentages for the resources

\begin{tabular}{lll}
\hline Resource & $\begin{array}{l}\text { Scheduled } \\
\text { utilization }\end{array}$ & Percentage idle \\
\hline ORI & 0.101932 & 89.81 \\
OR3 & 0.183589 & 81.64 \\
OR4 & 0.123607 & 87.64 \\
OR7 & 0.123607 & 87.64 \\
Surgeon I, ORTHO, R3 & 0.123607 & 87.64 \\
Surgeon I, ORTHO, R7 & 0.089855 & 91.01 \\
Surgeon 2, ORTHO, R3 & 0.03821 & 96.18 \\
Surgeon 2, ORTHO, R4 & 0.015987 & 98.4 \\
Surgeon 3, POD, RI & 0.037596 & 96.24 \\
Surgeon 3, POD, R3 & 0.02983 & 97.02 \\
Surgeon 3, POD, R7 & 0.010964 & 98.9 \\
Surgeon 4, ORTHO & 0.057574 & 94.24 \\
Surgeon 5, ORTHO, R3 & 0.084316 & 91.57 \\
Surgeon 6, ORTHO, R7 & 0.032637 & 96.74 \\
Surgeon 7, ORTHO, RI & 0 & 100 \\
Surgeon 7, ORTHO, R7 & 0.04327 & 95.57 \\
Surgeon 8, ORTHO, R7 & 0.044496 & \\
Surgeon 9, ORTHO, R3 & 0.044828 & \\
\hline & & 0.55 \\
\hline
\end{tabular}




\section{Conclusion}

The simulation results show that a podiatry patient has to wait $28.5 \%$ of the time an orthopedic patient would have to wait equivalent to an average 11.2 hours. The actual amount of time waited is of less importance because the simulation generates admission arrival based solely on the designated hourly arrival rate for a given cluster; it does not consider the time of the day, hence, an admission arrival could happen right after the operation rooms are closed for the day, and the patient would have to wait until the next day for an available operation room. The admission arrival was not modeled to happen only during a more realistic, limited time of the day because there is not enough information on the specific time a patient might arrive in reality. Waiting time is calculated in general for orthopedic patients and podiatry patients; waiting time for a specific operation room is unknown because the patients are modeled to wait for any available operation room, hence, they will not be waiting in the queue of a specific operation room.

All Surgeons had an extremely high idle time above $80 \%$ of the scheduled time. As for operation rooms, Operation room 1 has the highest idle time at $88.36 \%$ of its scheduled time. The best performing operation room was operation room 3 with $75.41 \%$ idle time. However, the simulation did not consider the time the operation room is being prepared for the operation or being cleaned up after the operation. Still, these idle percentages are extremely high. Arena Simulation software was used to replicate the arrival of patients for admission, consultation and procedures. The software successfully generated the patients' arrivals with percentage error $-0.90 \%$. The simulation results indicating an imbalance between the availability of the resources and patients' arrivals, causing an extremely high idle time. Moreover, the results also showed an imbalance between the resources dedicated to orthopedic patients and podiatry patients; podiatry patients are less in number but they wait longer than orthopedic patients do.

\section{Acknowledgments}

None.

\section{Conflict of interest}

Author declares no conflict of interest.

\section{References}

1. Beliën J, Demeulemeester E. Building cyclic master surgery schedules with leveled resulting bed occupancy. European Journal of Operational Research. 2007;176(2):1185-1204.

2. Bowers JA. Simulating waiting list management. Health Care Manag Sci. 2011;14(3):292-298.

3. Farahmand K, Esmeralda C. Cycle Time Reduction Using Simulation Optimization. Modeling, Simulation and Optimization (MSO 2004). 2004;29-53.

4. Yang Y, Sullivan KM, Wang PP, et al. Applications of computer simulation in medical scheduling. In Proceedings of the joint conference on information sciences. 2000;227. 